\title{
IT alignment: what have we learned?
}

\author{
Yolande E Chan ${ }^{1}$, Blaize Horner Reich ${ }^{2}$ \\ ${ }^{1}$ The Monieson Centre, Queen's School of Business, Queen's University, Kingston, Canada \\ ${ }^{2}$ Segal Graduate School of Business, Faculty of Business Administration, Simon Fraser University, Vancouver, Canada
}

Correspondence:

YE Chan, Queen's School of Business, Queen's University, Kingston, ON, Canada K7L 3N6.

Tel: + 1613533 2364;

Fax: + 16135332321 ;

E-mail: ychan@business.queensu.ca

\begin{abstract}
We provide a review of the alignment literature in IT, addressing questions such as: What have we learned? What is disputed? Who are contributors to the debate? The article is intended to be useful to faculty and graduate students considering conducting research on alignment, instructors preparing lectures, and practitioners seeking to assess the 'state-of-play'. It is both informational and provocative. Challenges to the value of alignment research, divergent views, and new perspectives on alignment are presented. It is hoped that the article will spark helpful conversation on the merits of continued investigation of IT alignment.

Journal of Information Technology (2007) 22, 297-315. doi:10.1057/palgrave.jit.2000109

Published online 18 September 2007
\end{abstract}

Keywords: alignment; linkage; fit; models; measures; antecedents; outcomes; strategy; structure; culture; knowledge; social dimensions

\section{Introduction}

$\mathbf{F}$ or two decades, IT alignment has consistently appeared as a top concern for IT practitioners and company executives (Luftman et al., 2005). Hundreds of commentaries and cases have been published in trade publications. Many scholarly journal articles have been published. So what have we learned?

In this article, we focus on the alignment literature within the MIS research discipline, reviewing past articles primarily of a scholarly nature - and proposing integrating views. Researchers, teachers, and practitioners alike should find this integration of the literature beneficial. For research, we suggest where future contributions might be made. For lecturers, we present alignment models that can be used in IT strategy classes to explain key concepts. In addition, we present the 'state-of-play' in alignment practice for lecturers and practitioners. For the latter, we also suggest ways to interpret the literature and implement research recommendations. We have tried to be both informational and provocative. Challenges to the value of alignment research, divergent views and new perspectives on alignment are presented. Our goal is to be as inclusive of major alignment perspectives as possible. ${ }^{1}$

We invite scholars and practitioners to contact the authors to provide additional information, similar and contrary views, and case studies. Via the Journal of Information Technology and AISWorld (http://www.isworld. org), we will summarize the feedback and stories we receive. Welcome to a conversation on IT alignment.
Structure of Article

In the article, we first discuss the motivation for alignment research. Next, we move on to define alignment and to present key dimensions and levels of the alignment construct. Our goal is to be inclusive of many different perspectives. We then present a review of various factor models of alignment and discuss antecedents and outcomes. We address the questions: What creates alignment? What benefits can reasonably be expected? Next, we present a process perspective on alignment and comment on different process models that have been researched. In closing, we provide reflections on the IT alignment research stream to date and highlight key implications for research and practice.

\section{Motivation and need for alignment research}

For many years, researchers have drawn attention to the importance of alignment between business and IT $^{2}$ (e.g., McLean and Soden, 1977; Henderson and Sifonis, 1988). In early studies, this often meant linking the business plan and the IT plan. Another perspective involved ensuring congruence between the business strategy and the IT strategy. Still another has required examining the fit between business needs and information system priorities. These conceptualizations have been enlarged over time and now research recognizes many points of alignment between business and IT. 
Early motivation for alignment emerged from a focus on strategic business planning and long-range IT planning in the early 1980s (e.g., IBM, 1981). From a business perspective, planning was characterized as a top-down and a bottom-up process, and departmental (e.g., IT) plans were created in support of corporate strategies. From an IT perspective, decisions on hardware and software had such long-term implications that tying them to current and future plans of the organizational unit was a practical necessity.

The business and IT performance implications of alignment have been demonstrated empirically and through case studies during the last decade (e.g. Chan et al., 1997; de Leede et al., 2002; Irani, 2002; Kearns and Lederer, 2003). Simply put, the findings support the hypothesis that those organizations that successfully align their business strategy with their IT strategy will outperform those that do not. Alignment leads to more focused and strategic use of IT which, in turn, leads to increased performance (Chan et al., 2006).

For all these reasons, academics have been motivated to study IT alignment. However, the motivation for and methods of alignment research have also been challenged.

\section{A counter-argument}

Many scholars argue that the alignment literature fails to capture important phenomena and that in fact, alignment is not always desirable. The arguments have several themes, including

(1) alignment research is mechanistic and fails to capture real life,

(2) alignment is not possible if the business strategy is unknown or in process,

(3) alignment is not desirable as an end in itself since the business must always change, and

(4) IT should often challenge the business, not follow it.

These arguments that challenge the need for further alignment research are described more fully below.

Ciborra $(1997)^{3}$ suggests that the alignment literature is too theoretical; that it is generated by the scientific method applied to the design of human affairs and computer systems. He recommends a Mintzberg-like approach, where researchers go to the field for insights (Mintzberg, 1973).

Critics of IT alignment research argue that in the world of work, alignment does not succeed because strategy is not a clear concept due to various turbulent, unpredictable circumstances that leave managers muddling through, betting, and tinkering with their corporate strategies (Vitale et al., 1986). Tightly coupled arrangements can have negative outcomes especially in turbulent times. That is, if the business environment suddenly changes and alignment is too tight, businesses may have difficulty adjusting to their new environments.

Furthermore, the use of technology itself is characterized by improvisations of various sorts (Ciborra, 1996; Orlikowski, 1996) and by unexpected outcomes. Working toward pre-specified or fixed outcomes may be unrealistic. In the worst case, this is an argument for the demise of alignment research. At best, this calls for an enlarged notion of alignment within a hybrid network of semiauto- nomous ( $v s$ harmonized and synchronized) actions (Ciborra, 1997).

Depending on the model of alignment, one can argue that it is necessary for IT to challenge the business, not simply implement its vision (Chan and Huff, 1993). Disagreement, friction, and conflict can be more desirable than reactive, smooth IT operations in order to achieve high business performance. This view suggests that researchers who believe that IT should simply support what the business is doing may be wasting their and others' time. However, Kearns and Lederer (2000) point out that while effective alignment of the IT plan with the business plan can provide competitive advantage, the opposite - aligning the business plan with the IT strategy - can result in potential losses. For this reason, researchers and practitioners must be cautious about putting IT in the lead.

Levy (2000), using a resource-based perspective, cautions that IT - even aligned IT - in and of itself is not strategic. In order for IT to be strategic, it must be valuable, unique, and difficult for competitors to imitate.

Sauer and Burn (1997) warn that alignment can give rise to pathologies that require careful management if undesired business and IT costs are to be avoided. Three types of pathological outcomes from strategic alignment are identified: misalignment, which occurs when a company tries to align IT with business strategies that are not internally consistent; IT stagnation, which occurs as part of a common, almost natural, cycle of innovation; and IT and globalization, which presents special scale and cultural difficulties for alignment. If IT researchers produce manuscripts that call for high alignment in these potentially difficult and pathological situations, they are doing a disservice to practitioners.

So should we abandon the study of alignment? The authors think not but welcome reader input. Although there are theoretical and empirically based arguments suggesting that alignment may not always be a suitable goal, the practitioner community consistently ranks it as a top priority. The Society for Information Management conducts surveys to gauge the importance of various IT issues. In 2005, the number one management concern of all groups of respondents was alignment (Luftman et al., 2005). Alignment was also ranked as the top management concern in 2004 and 2003, whereas it was ranked 9th in 1994, 7 th in 1990, 5th in 1986, and 7th in 1983. It is clear that the issue of IT alignment has remained important over the past two decades.

From the authors' perspective, the issues noted above are challenges to the attainment of alignment, rather than reasons alignment should not be pursued or studied. In this article, we take as given the view that alignment is inherently of value and contributes to organizational success. What we do not take for granted is that alignment is a static, single-dimensional factor or process, or that it is easy to attain. Our goal is to explore the many perspectives taken on alignment and to suggest ways in which academics and practitioners can integrate, build on and apply what has been learned.

\section{Challenges in attaining alignment}

Before outlining the approaches and benefits of alignment, we summarize alignment challenges from a practitioner's 
perspective. These challenges relate to knowledge, locus of control, and organizational change.

\section{Alignment challenges related to knowledge}

Challenges related to knowledge refer to the central problem that IT executives are not always privy to corporate strategy, and that organizational leaders are not always knowledgeable about IT. Also, managers are not always knowledgeable about key business and industry drivers.

Corporate strategy is unknown: A recurring issue seen in previous alignment research is that often corporate strategy is unknown (Reich and Benbasat, 2000) or, if known, is unclear and/or difficult to adapt (Baets, 1992). This poses a significant challenge because most models of alignment presuppose an existing business strategy to which an IT organization can align itself.

Formal business strategies are often too ambiguous for business managers to understand (Campbell, 2005). Managers face ambiguity surrounding the differences between espoused strategies, strategies in use, and managerial actions, many of which may be in conflict with one another. This issue of comprehension can be both internal and external to the IT organization. Internal comprehension is affected by mental models and world views, relationships, shared domains of knowledge, and shared systems of meaning. External comprehension is influenced by education and training, the organizational structure and visibility of the IT staff in the structure, and the IT environment. Failures or weaknesses in any of these areas may result in poor alignment.

Lack of awareness or belief in the importance of alignment : Although there is empirical support for the notion that alignment provides organizational value, many business managers are unaware of the importance of IT alignment and/or have little belief that IT can solve important business problems (Baets, 1996). For instance, in Baets' study of European banks, it was found that the influence of mindsets on IT alignment awareness was significant. Although there was a trend in the use of IT from a support function to a competitive capability, and IT issues were perceived to have a great influence on the banking industry, there was no strong and clear belief that IT could solve specific banking problems. Those managers who could see specific ways to solve banking problems via IT had more positive attitudes towards IT strategy and planning. Similarly, a study by Vitale and colleagues revealed a strong relationship between IT-knowledgeable management and system identification processes that were viewed as satisfactory (Vitale et al., 1986).

Henderson and Venkatraman (1993) found that managers were more comfortable with their ability to comprehend business positioning choices (i.e., where products are sold) rather than IT positioning choices (i.e., critical technology to support business strategies). This was attributed to the fact that strategy has typically been viewed as something applied to the output market, and that IT has typically been viewed as an internal response (or an input) to business strategy as opposed to something that leverages business strategy.

Lack of industry and business knowledge: Baets (1996) found IT alignment was hindered by a lack of knowledge about the banking industry (not just skills and knowledge about IT) among banking managers. In particular, it was found that IT alignment was negatively influenced by the following industry factors: (i) when awareness of the banking industry issues was low and (ii) when the interaction of different aspects within the corporate strategy was not well known to managers. Therefore, before managers could use IT solutions to help solve their banking problems, a deeper knowledge of the banking industry itself was required.

In a multiple case study of insurance business units, Reich and Benbasat (2000) showed that shared domain knowledge between business and IT executives was the strongest predictor of the social dimension of alignment. When shared domain knowledge was high, communication between the two groups was strategic and frequent, and the result was a high level of alignment.

\section{Alignment challenges related to locus of control and the status of IT}

Campbell et al. (2005) suggest that when managers are confronted with a business challenge, they make decisions based on their locus of comprehension (understanding) and their locus of control (authority to make decisions). These constraints impact alignment. From this perspective, strategic alignment can be seen as an array of bounded choices made in order to resolve strategic ambiguity (Campbell, 2005).

Another contributing factor in the attainment of alignment is the status of IT within the business unit or organization. In a study of cultural assumptions about IT, Kaarst-Brown and Robey (1999) found five separate archetypes. In several of these archetypes, notably the 'fearful' and the 'controlled', managers felt that IT was not a benign force within the organization. Therefore, although managers cognitively knew what was needed to achieve IT alignment, practically it was not feasible.

\section{Alignment challenges related to organizational change}

The business environment is constantly changing, and thus there may be no such thing as a 'state' of alignment. Strategic choices made by one organization frequently result in imitation by other organizations. Thus, strategic alignment is a process of change over time and continuous adaptation (Henderson and Venkatraman, 1993). Van Der Zee and De Jong (1999) cite a main problem with alignment as the time lag between business and IT planning processes. That is, given that the business environment and technology change so quickly, once an IT plan is enacted, there is a high probability that the plan and the technology are already obsolete.

Having presented challenges to alignment research and practice in organizations, we now turn our attention to defining alignment and presenting variance and process models. These definitions and models create a foundation for future alignment research. 


\section{What is alignment?}

\section{Alignment definitions}

Alignment has been conceptualized in the academic literature in various ways. Sauer and Yetton (1997) argue that its basic principle is that IT should be managed in a way that mirrors management of the business. ${ }^{4}$ Reich and Benbasat (1996) define alignment as the degree to which the mission, objectives, and plans contained in the business strategy are shared and supported by the IT strategy. Henderson and Venkatraman (1993) state that alignment is the degree of fit and integration among business strategy, IT strategy, business infrastructure, and IT infrastructure. McKeen and Smith (2003) argue that strategic alignment of IT exists when an organization's goals and activities and the information systems that support them remain in harmony. Good alignment means that the organization is applying appropriate IT in given situations in a timely way, and that these actions stay congruent with the business strategy, goals, and needs (Luftman and Brier, 1999).

When asking focus group participants to define alignment, Campbell (2005) was given the following answer: 'Alignment is the business and IT working together to reach a common goal.' Similarly, Abraham (2006) described alignment using a rowing analogy; 'Strategic alignment, is then, everyone rowing in the same direction.' These perspectives do not refer to visions, strategies, plans, structures, etc. that are mentioned in many academic definitions of alignment but their meaning is very clear. However, because of their lack of precision, they are less helpful in articulating what exactly constitutes good alignment and how it might be measured.

\section{Equivalent terms}

In the literature, alignment has also been called fit (Chan, 1992; Henderson and Venkatraman, 1993), linkage (Reich, 1993), and integration (Henderson and Venkatraman, 1993). Chan (1992) defined fit as the degree of coherence between realized business strategy and realized IT strategy. Henderson and Venkatraman (1993) defined fit in terms of the relationship between external business strategy and internal infrastructure and processes. They defined functional integration in terms of the business-IT relationship. Reich and Benbasat (1996, p. 56) defined linkage as 'the relationship between the business domain and the IT domain'. These terms and others (e.g., bridge (Ciborra, 1997), harmony (Luftman et al., 1999), and fusion (Smaczny, 2001)) are sometimes used interchangeably with alignment although subtle differences exist.

The term 'fit' has an extensive research stream in the mathematical and strategic management literatures (e.g., see Edwards, 1992). In the MIS literature, it has often, but not exclusively, been used to refer specifically to the measurement of alignment (e.g., Bergeron et al., 2001). Although it may be argued that 'alignment' is now the dominant term in the MIS literature, this cannot be said for the strategy literature where we also find extensive use of terms such as fit, congruence, and covariation.

\section{Alignment dimensions}

In the MIS literature, several dimensions of alignment are clearly apparent: strategic/intellectual, structural, social, and cultural. Although significantly more attention is given to strategic IT alignment, both strategic alignment and structural alignment influence performance. In addition, alignment is contingent on many of the social and cultural aspects of an organization (Reich and Benbasat, 1996; Chan, 2001).

\section{Strategic and intellectual dimensions}

Strategic alignment refers to the degree to which the business strategy and plans, and the IT strategy and plans, complement each other. Reich and Benbasat (2000) define intellectual alignment in terms of 'the state in which a highquality set of inter-related IT and business plans exist.' With this perspective, it is difficult for alignment to occur if the business lacks a formal, documented plan (Vitale et al., 1986; Lederer and Mendelow, 1989; Wang and Tai, 2003).

Kearns and Lederer (2000) argue for a distinction between the information systems plan (ISP)-business plan (BP) and BP-ISP model of alignment. The ISP's alignment with the BP, or the ISP-BP model, signifies IS management's understanding of business strategy (Reich and Benbasat, 1996). The BP-ISP alignment model, on the other hand, ensures that the business plan reflects the experience and knowledge of the organization utilizing ITbased resources, and signifies better top management understanding and commitment (Bensaou and Earl, 1998).

\section{Structural dimensions}

Structural alignment refers to the degree of structural fit between IT and the business. Structural alignment is influenced by the location of IT decision-making rights, reporting relationships, (de)centralization of IT, and the deployment of IT personnel (Chan, 2002). Pyburn (1983) found that IT is much more likely to be perceived as supporting the critical needs of the business when there are few levels between senior management and IT management.

Earl (1989) outlined five ideal IT arrangements: centralized, business unit, business venture, decentralized, and federal. In this model, 'arrangement' connotes the structures, processes, and accommodations that evolve when organizing IT. These arrangements need to be aligned with factors such as the host organization characteristics, technology assimilation, the strategic impact of IT, and the IT heritage.

Brown and Magill (1994) suggested a simpler structural typology involving IT structures that are centralized, decentralized, or hybrid. They provided evidence that each structure can be effective, given the right circumstances. In their study, the choice of a decentralized IT structure was influenced by a corporate strategy of unrelated diversification, a decentralized overall firm structure, a culture of strong autonomy without the desire for a CIO, satisfaction with the management and use of technology, and total business unit control over system approvals. The choice of a centralized IT structure resulted from a corporate strategy of related diversification, an overall firm structure of hybrid strategic business units, a culture of central direction, a CIO who was part of the top management team, satisfaction with 
the management and use of technology, and some business unit control of systems approvals.

Empirically, Tavakolian (1989) found that IT structure is strongly related to competitive strategy. That is, firms that have a conservative strategy tend to have a centralized IT structure. Those firms that are more entrepreneurial and risk-taking tend to have a decentralized IT structure. Bergeron et al. (2001) found that increasing structural complexity alone has no impact on performance. That is, more complex IT structures are not necessarily superior. However, increasing structural complexity in conjunction with a stronger IT management can increase competitive positions in terms of growth and profitability.

\section{The informal structure}

Although the formal structure is most often researched, Chan (2001) found the informal structure to be of great importance in improving IT alignment and performance. The informal structure was defined as 'relationship-based structures that transcend the formal division of labor and coordination of tasks'. Chan's study suggested that scarce management time and resources are better spent on improving the informal organization than on aligning formal structures. Although less visible than the formal structure, it can be more malleable and paradoxically more enduring.

\section{Social dimension}

Reich and Benbasat (2000) define the social dimension of strategic alignment in terms of 'the state in which business and IT executives within an organizational unit understand and are committed to the business and IT mission, objectives, and plans.' They argue that researchers should study the social and intellectual dimensions of alignment together. This will reveal the complexity and challenges of IT alignment.

There are many barriers to achieving both intellectual and social dimensions of alignment and the prerequisite strong CEO-CIO relationship (Feeny et al., 1992). IT personnel and business staff must collaborate together at all levels of an organization. This is a prerequisite for high alignment. Yet this may be hindered by many issues such as the invisibility of the IT staff, communication barriers, history of IT/business relationships, attitudes of organization members to IT, shared domain of knowledge, and leadership (Earl, 1989; Campbell, 2005).

\section{Cultural dimension}

Pyburn (1983), in an early study on strategic IT issues, points out the importance of cultural fit between business and IT as a precondition for successful IS planning. He argues that IS planning can validly adopt a personalinformal or a written-formal approach, but that it needs to be aligned with cultural elements such as the business planning style and the top management communication style to be effective.

In essence then, alignment needs to be culturally supported; otherwise, it is a never-ending quest. Chan (2002) suggests that a strong company culture is a precondition to the type of informal structure that fosters alignment. Tallon (2003) emphasizes the need for a mind-set that encourages shared networks and common IT procurement policies, and an across-the-board willingness to give up incompatible bestof-breed systems. He states that the 'alignment paradox' cannot be avoided just by picking certain technologies and avoiding others. Flexibility takes vigilance and smart management approaches.

Alignment is then fundamentally about cultural change and behavior change (CIO Insight Staff, 2004). There has to be commitment from top management for alignment to work. People are not going to listen to what the CIO says as much as they are going to watch what the CIO does, and what the CIO's business partners do. IT personnel need to be skilled in the softer side of business, which often does not go hand-in-hand with the engineering focus of IT professionals. Top management buy-in, proactive CIOs, and socially adept IT professionals are vital for making alignment a cultural phenomenon.

Van Der Zee and de Jong (1999) and CIO Insight Staff (2004) raise the issue of the lack of a common 'language' between business and IT executives. They cite the need to build bridges so that both IT and business personnel are using the same terms, talking about the same topic, which in turn assists with alignment in thought and action. Hunt (1993) states that in well-aligned firms, top management welcomes what can be done through IT, using their understanding of the particular business issues in their company and their imagination when conceiving ITenabled business strategies.

Burn (1993) advocates a cultural audit to examine the relationships between organizational and IT strategy formulation processes. Burn suggests two independent audit checks: one to review the alignment of organizational strategy and structure, and the other to review the alignment of IT strategy and structure. The two audit checks, when applied together, are referred to as the organizational 'cultural' audit framework.

\section{Levels of alignment}

Ideally, alignment should be present at all levels of the organization, including the organizational level, system level (Floyd and Woolridge, 1990; Campbell, 2005), project level (Jenkin and Chan, 2006), and the individual/cognitive level (Tan and Gallupe, 2006).

According to Floyd and Woolridge (1990), misalignment can often explain system implementation difficulties. Formal strategies are often only implemented at the upper levels of the organizations, yet strategy is carried out on the front line. The focus of alignment at the lower levels of an organization involves translating business unit goals into personal goals (Campbell, 2005).

Recognizing this problem, Bleistein et al. (2006) attempt to use requirements engineering to link higherlevel strategic goals to lower level, explicit organizational processes. Their model provides a mechanism for verifying alignment as requirements are explicitly verified with super-ordinate goals and subordinate goals.

Jenkin and Chan (2006) examine alignment at the project level. They define IT project alignment as the degree to which an IT project's deliverables are congruent with the organization's IT strategy and the project's objectives. Critical to project alignment is the project's response to 
change triggers. These triggers can be both internal (e.g., a mid-term project evaluation) and external (e.g., a change in the operating environment). Failure to respond to change triggers effectively leads to project misalignment. Project misalignment can trickle upwards, leading to overall IT strategic misalignment.

Tan and Gallupe (2006) operationalize alignment, at its most micro-level, as shared cognition between the business and IT executives. That is, the higher the level of cognitive commonality between business and IT executives, the higher the levels of IT-business alignment. Similarly, the greater the diversity in the cognitive structure and content of business and IT executives, the lower the expected levels of alignment. This perspective has strong parallels with the social dimension of alignment, based on shared domain knowledge (Reich and Benbasat, 2000). It also reflects a view of business-IT alignment in which IT mirrors ( $v s$ challenges) ongoing business activities.

\section{Internal $v$ s external alignment}

Earl (1989) proposes that IT strategy and infrastructure should be aligned with information systems strategy (i.e., the applications and information) within an organization. Henderson and Venkatraman (1993) assert that alignment must be both internal and external to the organization. Externally, organizations must align their business and IT strategies with industry and technology forces while internally organizations must align organizational and IT processes and infrastructure. Sledgianowski and Luftman (2005) recommend as an alignment best practice that organizations should leverage IT assets on an enterprisewide basis to extend the reach (the IT extrastructure) of the organization into supply chains of customers and suppliers. Similarly, Galliers (2004) suggest that alignment is not just related to internal challenges, but should also influence and be influenced by relationships with crucial partner organizations such as customers and suppliers.

\section{Alignment measures}

The measurement of alignment is important for several reasons. For practitioners, if alignment can be measured, it can more readily be managed. For academics, reliable and valid measures are important if alignment investigations are to be rigorous. In the MIS literature, several different approaches have been used to assess alignment, including typologies and taxonomies, fit models, survey items, mathematical calculations, and qualitative assessments. These are outlined below.

\section{Typologies and taxonomies}

While typologies are deductive, intuitive groupings or classifications of phenomena, taxonomies are groupings based on the results of inductive, empirical analyses (Chan, 1992). Sabherwal and Chan (2001) use the Miles and Snow (1978) strategy typology to measure business strategy, predict the appropriate IT strategy, and assess alignment. For Defenders (see Miles and Snow, 1978), they expected theoretically to see 'alignment for IS efficiency', for Prospectors, they anticipated 'alignment for IS flexibility', and for Analyzers, the expectation was 'alignment for IS comprehensiveness'. They were able to compute detailed typology-based alignment assessments when they empirically examined real-life business and IT strategies. Using similar mathematical techniques, Sabherwal and Kirs (1994) demonstrate how to compute misalignment, the opposite of alignment, using weighted Euclidean distances of IT capability variables from an ideal profile.

\section{Different fit models}

Venkatraman (1989) discusses six different conceptualizations of fit in strategy research:

1. moderation - calculated using interaction terms

2. mediation - modeled using indirect or intermediate variables

3. matching - measured using difference scores

4. gestalts - arrived at via cluster analysis

5. profile deviation - examined using pattern analysis

6. covariation - computed using factor analysis.

Bergeron et al. (2001) examine these six conceptualizations of fit in IT research. They argue that studies which neglect to specify the exact perspective of fit may lead to contradictory, mixed, or inconsistent results (Bergeron et al., 2004). In addition, specifying one type of fit conceptually and then using measures designed for another type of fit introduces errors. Cragg et al. (2002) provide evidence of inconsistent results from two different measurement approaches, the matching perspective and the moderation perspective. They also argue the importance of selecting appropriate alignment models.

Chan et al. (1997) developed the STROIS (Strategic Orientation of IS) instrument based on an earlier STROBE (Strategic Orientation of Business Enterprises) instrument by Venkatraman (1989). The Chan et al. (1997) study provides empirical support for modeling IT strategic alignment using a moderation or synergistic approach rather than a simple matching or mirroring approach. Assessing the alignment of business strategy and IT strategy based on the combination of STROBE and STROIS ${ }^{5}$ has subsequently been carried out by others (e.g., Ma and Burn, 1998; Cragg et al., 2002). In the Cragg et al. (2002) study, to maximize related benefits, IT alignment was modeled as the interaction between business strategy and IT strategy (i.e., as a moderation variable), rather than as a simple match between the two.

Questionnaire items: Many IT studies have simply posed the question, 'On a scale of $1-5$, how do you rate IT alignment in your organization?' While this can be helpful as a single indicator of overall alignment, more detailed scales provide greater reliability and validity. Kearns and Lederer (2003) developed a 12-item measure of alignment. This scale measures the alignment of the IT plan with the business plan (six items) and the alignment of the business plan with the IT plan (six items). Bergeron et al. (2004) developed a questionnaire to measure IT strategy and IT structure. Their measure included dimensions of IT environment scanning, IT planning and control, and IT acquisition and implementation. After testing 66 initial items, a final measure of 29 items was retained.

The Organizational Culture Audit (OCA) is another questionnaire-based method for measuring alignment 
(Burn, 1993, 1996). As alignment is an ongoing process, the OCA instrument is completed annually by different managers. This yearly review and change in respondents' opinions provide a robust picture of alignment in an organization. Six relationships in particular are examined: the external strategy and the IT strategy, the internalinfrastructure model for business and IT, and planning models for internal and external cross-alignment.

Other mathematical calculations and models: There are many other quantitative mechanisms to assess alignment in the literature. For instance, Day (1996) argues for the following three measures:

1. Alignment measurements - Alignment indices that are used to determine how effectively the IT function is supporting the company's overall goals at the strategic level.

2. Alignment index - A simple comparison of the IT activities to stated business goals. In making the comparison, a percentage value should be assigned, based on a scale of 1-100, that represents the subjective evaluation of how well aligned each activity is with the business objective it supposedly serves.

3. Effectiveness acid test - A direct comparison between the proportion of IT expenditures devoted to specific P\&L ${ }^{6}$ line activities and the volume of each activity expressed as a percentage of sales. These two figures should be similar in magnitude over time.

It is not possible to completely list the quantitative models and tests of alignment used in research and industry. The authors welcome details of these tests and hope to make them available to future readers with the assistance of the Journal of Information Technology.

Qualitative measures: To complement quantitative assessments, researchers and practitioners make rich, qualitative judgments regarding the state of IT alignment in organizations. Reich and Benbasat (1996) compare several measures of the social dimension of alignment, including alignment of written business and IT plans, self-reports, mutual understanding of current objectives, and congruence in long term business and IT visions. They validate two out of four proposed measures of linkage, namely understanding of current objectives (short term alignment) and congruence in IT vision (long term alignment). In their study, written IT and/or business plans often did not exist and self-reports needed to be used with caution.

Psychological measures: Tan and Gallupe (2006) examine shared cognition as a proxy for alignment. Using cognitive maps between business and IT executives (Tan and Hunter, 2002), they find that higher cognitive commonality is related to higher levels of alignment.

\section{Alignment models}

While measures are granular and descriptive, we view models as more holistic and prescriptive. In this section, we present only the few alignment models that have been particularly influential. We focus on a stream of research emerging in parallel from North America and Europe in the early 1990s. Many studies since then have used concepts from these models. Because of space constraints, several other important models have not been described. ${ }^{7}$

Initially, IT served primarily in a 'back office' or support role capacity. However, with the advancement of technology, many saw the potential for IT to perform a more strategic function. Research conducted in the 1980s at MIT (Scott Morton, 1991) served as an initial attempt to harness the strategic power of IT. The MIT model (see Figure 1) argues that revolutionary change involving IT investment can bring about substantial rewards as long as the key elements of strategy, technology, structure, management processes and individuals and roles are kept in alignment.

Henderson and Venkatraman (1992) were influenced by the MIT research in their creation of the Strategic Alignment Model (SAM), which is perhaps the most widely cited of all alignment models. ${ }^{8}$ The SAM model is based on four related key domains of strategic choice, namely business strategy, organizational infrastructure and processes, IT strategy, and IT infrastructure and processes (see Figure 2).

In the SAM model, the concept of strategic alignment is distinct from bivariate fit (i.e., linking only two domains) and cross-domain alignment (i.e., linking any three domains). A distinction is also drawn between the external perspective of IT (IT strategy) and the internal focus of IT (IT infrastructure and processes). The potential of IT to both support and shape business policy is recognized (Henderson and Venkatatram, 1992).

The SAM model has received empirical support and has conceptual and practical value (Goedvolk et al., 1997; Avison et al., 2004). However, it has its limitations. For instance, depending on how IT-intensive an industry is, the model's applicability may vary, as the assumptions of the SAM model may not hold (Burn and Szeto, 2000).

Several scholars have built on and extended the SAM model (e.g., Luftman et al., 1993). Goedvolk et al. (1997) extend the SAM model by focusing on technical and architectural requirements. Avison et al. (2004) add to the

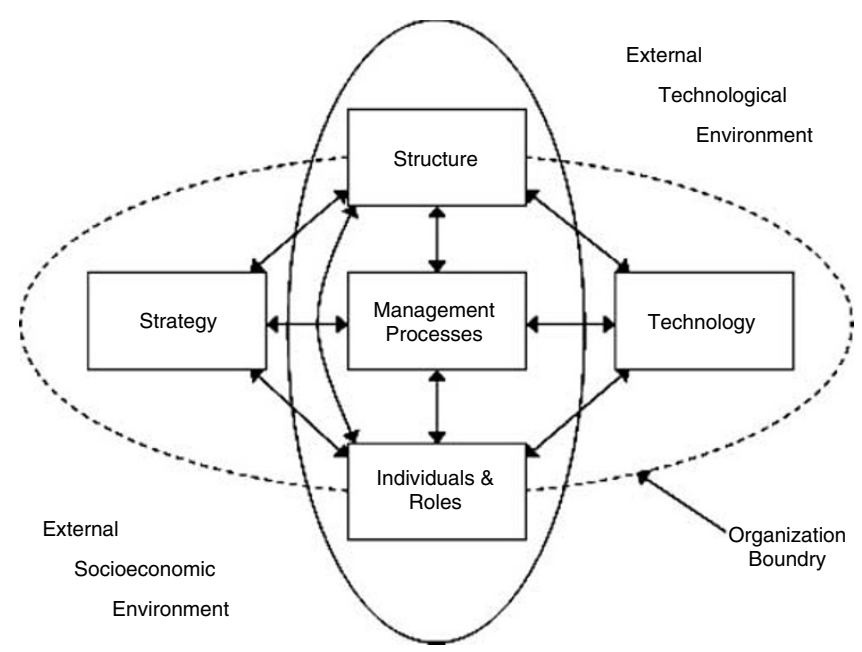

Figure 1 The MIT90s framework. Reprinted from Morton, M.S.S. (1991) Introduction, in M.S.S. Morton (ed.) The Corporation of the 1990's, page 20, with permission from Oxford University Press. 


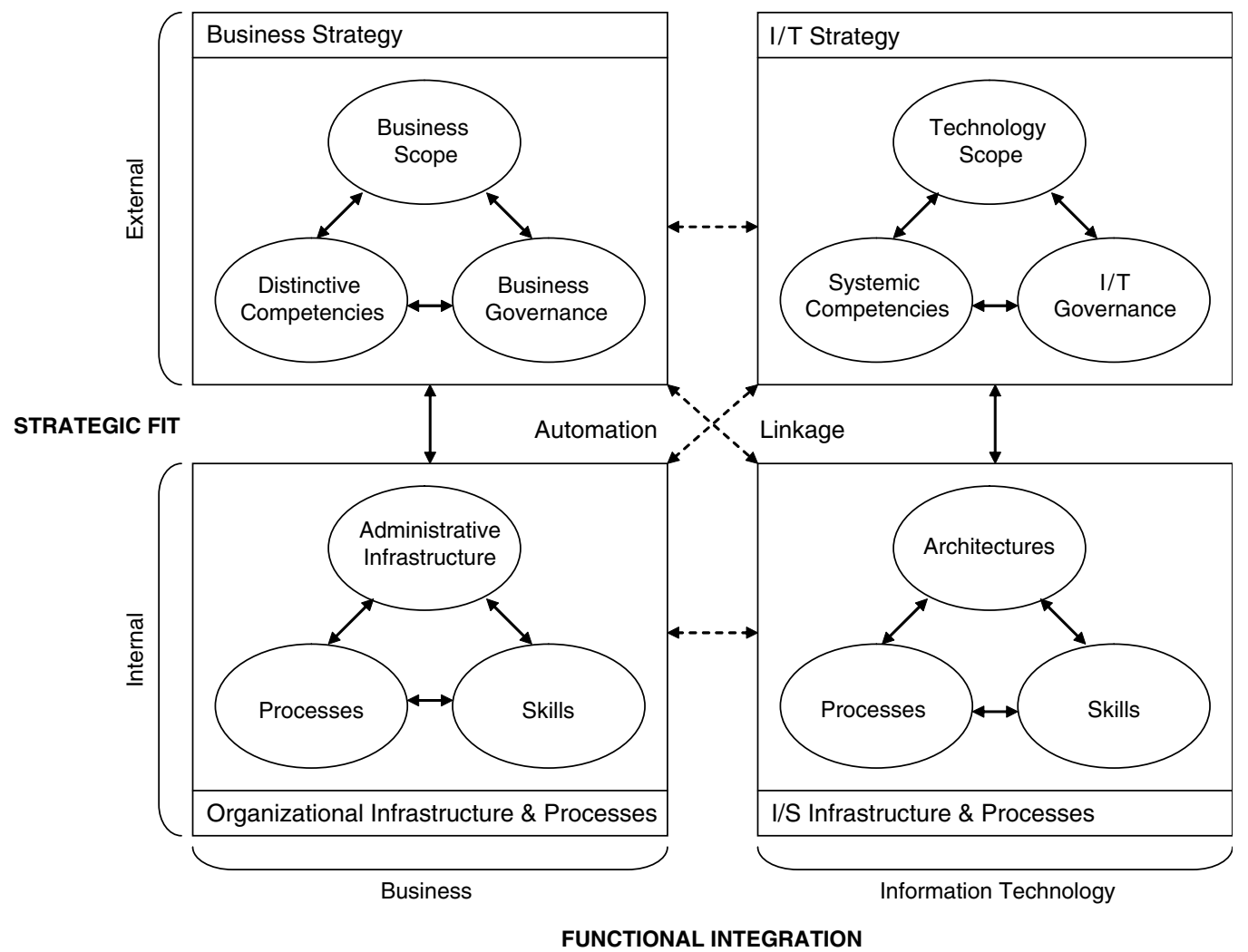

Figure 2 The Henderson and Venkatraman strategic alignment model. Reprinted from Henderson, J.C. and Venkartraman, N. (1993) Strategic Alignment: Leveraging information technology for transforming organizations. IBM Systems Journal 32(1): 476, with permission from IBM Technical Journals.

SAM model, providing managers and researchers with additional practical ways to attain alignment. They advocate examining projects worked on over a previous period, and in this way retrospectively determining alignment. This approach can be used to monitor alignment, pre-empt a change in strategy and implement a new alignment perspective by re-allocating project resources.

Maes (1999) and Maes et al. (2000) also extend the SAM model, producing a framework that incorporates additional functional and strategic layers. They separate information providers from the systems that provide information. A new information domain represents the knowledge, communication and coordination of information. They also add a third dimension that contains specific sub-architecture areas.

The MacDonald (1991) ${ }^{9}$ model, building on MIT 1990s Framework also examines inter-relationships between business and IT strategy, infrastructure and processes. External impacts on customers, suppliers, and markets are considered. MacDonald argues that in order to achieve alignment, various cycles must be run. In cycle 1, the stages include competitive potential, business value, service level, and technology potential. In cycle 2 , the stages created in cycle 1 are reviewed.

Baets (1992) developed a model of alignment adapted from the alignment models of MacDonald (1991) and the enterprise-wide information model (Parker et al., 1988). Like the SAM model, it depicts the interaction of business strategy, organizational infrastructure and processes, IS infrastructure and processes, and IT strategy (see Figure 3). Baets's model also recognizes that alignment takes place in a broader context and incorporates factors such as competition, organizational change, human resource issues, the global IT platform, and IS implementation processes.

Baets (1992) does challenge a SAM assumption of participant awareness of the economic environment and the corporate strategy. He argues that in most organizations, there is not a monolithic, widely accepted strategy and further, that most organizational members do not know the strategy.

It is not surprising that the Baets (1992), Henderson and Venkatraman (1992), and MacDonald (1991) models have strong similarities. At their roots lie the MIT Framework of the 1990s and the strategic IS planning literature (e.g., Galliers, 1988).

The alignment models presented here are just a small (albeit important) sample of the several models in the literature today. Readers wishing to have information on other models are invited to examine the Annotated Scholarly Bibliography of IS Alignment Research also published in this issue of the Journal of Information Technology.

\section{Variance models: antecedents and outcomes}

\section{Introduction}

In the academic literature, alignment has been seen both as a construct to be measured at a single point in time (e.g., in 


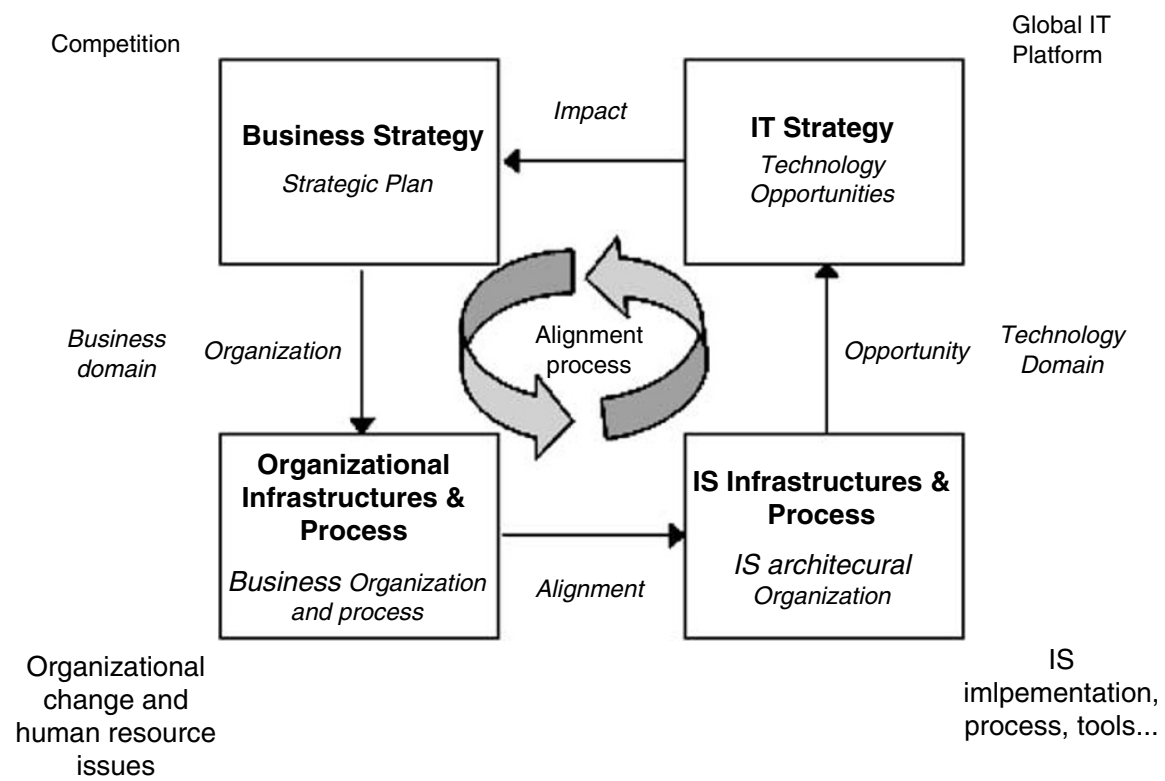

Figure 3 The Baets model. Reprinted from Baets W. (1992) Aligning Information Systems with Business. The Journal of Strategic Information Systems 1(4): 207, with permission from Elsevier.

a cross-sectional study using a variance or factor ${ }^{10}$ model) and as a process to be understood over time. In this section, we focus on factor models, highlighting antecedents or drivers of alignment and then turn our attention to the outcomes that can be expected when alignment is achieved. In the section that follows, process models and variables are described.

\section{Antecedents to alignment}

Here, we highlight influential background antecedents such as corporate culture, shared knowledge, and prior experience with IT. We also highlight foreground, that is, visible behaviors that influence alignment. These include, for example, leadership approaches, planning processes, and communication styles. We acknowledge that these antecedents overlap and are interdependent.

\section{Background antecedents}

Reich and Benbasat (2000) found that two background factors - shared domain knowledge and IT implementation success - influenced behaviors such as communication between IT and business executives and connections between IT and business planning. These four factors were antecedents to short-term alignment but only shared domain knowledge was an antecedent to long-term alignment. In addition, the existence of clear business plans influenced both short-term and long-term alignments.

In another study, Chan et al. (2006) examined antecedents to alignment directly under the control of IT management (such as shared domain knowledge, planning sophistication, and the credibility of the IT group due to prior IT success), and factors external to the IT group such as organizational size and environmental uncertainty. In earlier research, Brown and Magill (1994) identified antecedents such as corporate vision, strategic IT role, satisfaction with management of technology, satisfaction with the use of technology, and the locus of control for system approvals.

\section{Foreground antecedents/behaviors}

According to Baker (2004), successful alignment between business strategy and IT requires strong leadership. Baker asked executives to indicate whether their company's management style was autocratic, collaborative, or indecisive. Most firms led by collaborative managers indicated that their company's IT was well aligned with business strategy. On the other hand, managers in firms with autocratic or indecisive leadership reported a lower level of alignment.

Feeny et al. (1992) established the importance of the relationship between the $\mathrm{CEO}$ and the CIO. In firms with successful CEO-CIO relationships, the CEO tended to have had a career background in marketing or general management, employed change-oriented leadership, attended IT awareness-raising seminars, experienced IT project success, perceived IT as critical, and positioned IT as an agent of business transformation. In relationships that were successful, the CIO had spent his/her career in IT, promoted IT as an agent of business transformation, contributed beyond the IT function, accurately perceived the CEO's views on business and IT, integrated IT with business planning, and emphasized consultative leadership and creativity.

Lederer and Mendelow (1989) found that IT executives were successful only if supported by the top management. For instance, alignment improved as a result of the CEO encouraging business participation in IT planning, the establishment of an IT plan, and IT management's participation in business planning.

In most firms, documenting the business plan facilitates alignment. Simply put, alignment cannot readily occur if the business lacks a formalized strategic business plan in 
the first place (Vitale et al., 1986; Lederer and Mendelow, 1989; Reich and Benbasat, 2000; Wang and Tai, 2003). Clearly defined business goals and vision are often first steps in an alignment process. In a study of small manufacturers, Cragg et al. (2002) found that many of the manufacturers had achieved a high degree of alignment between their business strategy and IT. While two-thirds of the sample had a written business plan, only a quarter had formalized their IT strategy. So while IT planning existed in small firms, much of it was carried out informally (Lefebvre and Lefebvre, 1988).

Teo and Ang (1999) list 12 success factors that are critical for aligning IT plans with business plans. These items (see Table 1) are a mix of interdependent background and foreground antecedents. For instance, one could argue that 2 (IT's knowledge of the business) and 5 (frequent ITbusiness communication) relate to 11 (the IT department being able to use IT creatively and strategically) and 9 (a responsive IT department).

Lederer and Mendelow (1989) found that coordination of the IT plan and the business plan were achieved in three dimensions (Shank et al., 1973): plan content, timing, and personnel. Chan et al. (2006) found that planning sophistication or comprehensiveness led to an increase in shared knowledge, which in turn affected alignment. The more sophisticated the planning process, the greater the likelihood of involvement of personnel from different areas of expertise. This in turn led to improved shared knowledge and ultimately alignment.

Luftman et al. (1999) examined the enablers and inhibitors of alignment. Their research suggested that:

1. Factors that IT executives can directly impact are project priority setting, IT knowledge of the business, and IT leadership.

2. Factors under business control are IT involvement in strategy development, and senior executive support for IT.

3. Both business and IT have to foster a close working relationship.

Table 1 Critical success factors for aligning IT plans with business plans from Teo and Ang (1999)

1. Top management commitment to the strategic use of IT

2. Top management's confidence in the IT department

3. Top management's knowledge of IT

4. IT management's knowledge of business

5. Business goals and objectives that are known to IT management

6. The corporate business plan being available to IT management

7. The IT department being able to identify creative ways to use IT strategically

8. IT staff who are able to keep up with advances in IT

9. Frequent communication between users and IT departments

10. Business and IT management partnering to prioritize applications development

11. The IT department's efficiency and reliability

12. An IT department that is responsive to user needs
Campbell (2005) and Reich and Benbasat (2000) identified communication as a key antecedent to alignment. Communication was often associated with understanding, which in turn increased the locus of comprehension. The argument exists that the typical IT person lacks good communication skills. Campbell suggested this might be a myth and pointed out that even if some IT personnel wanted to communicate they would not be allowed to. Organizations using a technocratic coping response, as opposed to a collaborative coping response, could discourage communication between themselves and the IT group.

Sledgianowski and Luftman (2005) noted that communication should be a fundamental and regularly occurring task of all managers and employees. For alignment, business-IT communication should regularly occur and be pervasive throughout the organization. They argued that it should also be informal and should use appropriate methods such as e-mail, videoconferencing, and faceto-face communications.

\section{Alignment capabilities}

Gupta et al. (1997) demonstrated that alignment between a firm's competitive strategy and IT management strategies can be translated into a particular set of distinctive competencies in IT management for each competitive strategy. They argued that there is no one solution for alignment problems. Rather, it is the alignment capabilities possessed by an organization that enable it to leverage technology to gain competitive advantage.

Street (2006) looked at how alignment capabilities developed over time and how they could be measured. He developed measures for seven alignment capabilities: IS service matching, environmental IT scanning, assessing alignment, building stakeholder commitment, IT filtering, prioritizing IT resources, and strategic IT experiments. He found that in organizations that had experienced episodes of punctuated change, their alignment capabilities were weakened by the change. Those that did not experience punctuations continually 'thickened' or strengthened their capabilities over time.

\section{Outcomes of alignment}

Henderson and Venkatraman (1992) argue that strategic alignment can influence organizational transformation in a descriptive sense (i.e., by illustrating the value of emerging IT), prescriptive sense (i.e., by grounding cases in a theoretical framework and suggesting possible courses of action), and in a dynamic sense (i.e., by conceptualizing major relationships and interactions to be addressed over time). Technology influences the power and reach of organizations. High performing organizations often have developed capabilities to harness and align IT (Scott Morton, 1991). IT alignment is a management concern primarily because of its potential impact on firm performance. In this section, we focus on organization and industry-level outcomes.

\section{Organizational performance}

Strategic IT alignment leads to increased profits for an organization, above and beyond what would be expected to 
be produced using only industry and strategy variables (Floyd and Woolridge, 1990; Powell, 1992; Chan et al., 1997; Cragg et al., 2002). Sabherwal and Chan (2001) found that alignment is significantly correlated with perceived business performance, although this link is complex and is dependent on the business strategy. For Defender strategies, they uncovered no significant relationship between alignment and performance, whereas the alignment-performance relationship was observed for Prospectors and Analyzers.

Yetton (1994) concluded that if the separation of business and IT was substantial, company performance suffered. This separation contributed to organization's failing to learn how to manage IT investments and extract value from them. Similarly, Sauer and Burn (1997) argued that when business decisions were made without consideration of IT, there was a risk of pathological or damaging outcomes.

However, not all evidence concludes that alignment has direct or positive performance implications. Tallon (2003) found that while $70 \%$ of companies reduced costs or improved sales and customer service after increasing strategic alignment, $30 \%$ saw no improvement or even a decline. This was attributed to the failure of alignment to be achieved with some degree of flexibility. That is, companies locked themselves into an alignment plan (via investing in various technologies) that hindered their ability to react to change. Similarly, Palmer and Markus (2000) did not find a relationship between alignment and performance when examining the use of Quick Response technology in the retailing sector.

It has been argued that these negative or unclear results are due to a lack of control variables in the analyses. Chan et al. (2006) found that factors such as industry, organizational size, and type of strategy all had an impact on the performance implications of alignment. Byrd et al. (2006) found that strategic alignment had a direct impact on performance as a moderator between IT investment and business performance. The real value in alignment was in leveraging the firm's IT investment.

\section{Industry performance}

Strategically well-aligned IT can change industries. Wellknown examples include American Airlines's SABRE reservation system, the Bank of America's ERMA automatic cheque processing system, and American Hospital Supply/ Baxter. By increasing the scope and impact of IT in these organizations, the industry structure was transformed causing significant market shifts (McKenney et al., 1995). The impacts of alignment go beyond firm boundaries.

\section{Contingency perspectives}

We have discussed the antecedents and outcomes of IT alignment as documented in the literature. However, contingency theory posits that there is no universally superior strategy or way to organize in a given context or environment (Venkatraman, 1989); rather, the context and structure must fit together if an organization is to perform well (Drazin and Van de Ven, 1985). Applied to IT alignment, contingency theory tells us that certain contextual and organizational factors fit together to facilitate alignment. Thus, certain business and IT factors, when combined in certain contexts, produce superior performance. We present several contingencies in this section.

\section{Industry}

Chan et al. (2006) found that important antecedents to alignment were contingent on the industry in which the organization operated. In their study, business and academic institutions were compared. Organizational size had little impact on alignment in academic institutions and environmental uncertainty had limited impact on alignment in for-profit businesses.

Alignment can be more difficult in industries with quick clock speeds, when there are economic downturns and scarce resources, for certain organizational strategies, and at certain points in the organizational life cycle. Peak et al. $(2005 a, b)$ found that deregulation can serve as a powerful motivator for companies in those industries to align their IT with their business strategies. In their study, the increased competition that came with deregulation highlighted the importance of alignment.

Tan (1995) found that IT is more responsive to business strategy in those organizations that emphasize innovation in their product and market strategies, as opposed to organizations operating in a relatively stable product/ market area.

\section{Organizational size}

While very small firms may be well aligned because the level of communication is high and individuals play multiple roles, medium-sized institutions frequently show less evidence of alignment. As organizations continue to grow in size and complexity, more formal planning processes are enacted to help ensure an integrated vision for IT. In larger organizations, managers more commonly introduce formal processes and structures to ensure alignment (Hale and Cragg, 1996). Larger firms tend to have more slack, which can be devoted for alignment purposes. Therefore, large firms may also be well aligned. Chan et al. (2006) found that alignment increased as organization size increased, but only in business (as opposed to academic institutions). This result was explained by institutional theory as academic institutions tend to function similarly regardless of size.

Raymond et al. (1995) found that greater sophistication in the use of IT was significantly associated with better performance. However, the results revealed the importance of size and environmental uncertainty as crucial contingency factors. Firms with larger sizes that perceived their environment to be more uncertain tended to have greater IT sophistication, which in turn allowed these firms to respond better to complexity or growth.

\section{Strategic orientation}

The Miles and Snow (1978) typology of business strategy, commonly used in the alignment literature classifies businesses as either taking on a Prospector, Analyzer, Defender, or Reactor strategy. Tan (1995) found that prospectors and defenders differ in the extent to which IT is explicitly considered in shaping business strategy. The 
more aggressive the business strategy, the more IT is explicitly viewed as a strategic tool.

Croteau and Bergeron's (2001) study indicated the existence of a link between strategic activities, technological deployment, and organizational performance. This relationship, however, took different shapes depending on the type of business strategy. The study indicated that organizations could enhance performance by supporting prospector or analyzer strategies with IT. Organizations with analyzer strategies could make effective use of IT by encouraging personnel to read journals specific to IT, participating in professional associations, and being educated regarding the application of new technologies. Organizations with prospector strategies generally did not use technology as their primary driver and did not regularly scan the IT environment, but did recognize the importance of having the IT department participate in strategic meetings. Defender and reactor organizations, however, did not experience this relationship in the first place, and thus technology was less helpful for them.

Similarly, Chan et al. (2006) found that the type of business strategy had an impact on the importance of alignment. In their study, prospectors generally had lower levels of alignment than analyzers, and were less affected by environmental uncertainty.

\section{Turbulence}

Environmental uncertainty, or the degree of change and instability in the firm's operating context, has an impact on alignment (Tallon and Pinsonneault, 2005). In times of high environmental uncertainty, organizations have a stronger need for information and information systems. It is expected that organizations will invest heavily in IT alignment during times of environmental uncertainty (Johnston and Carrico, 1988) and may be able to derive greater benefits from IT (Sabherwal and Kirs, 1994). So environmental turbulence affects the importance of IT alignment, the ease with which it is achieved, and the mechanisms for achieving it.

Vitale et al. (1986) found that turbulence associated with frequent changes in products, suppliers, customers, production processes, or competitive environment made topdown planning more difficult. Moreover, such turbulence decreased the utility of the top-down planning process as an instrument for identifying competitive applications of information technology. In order to avoid some of the issues associated with top-down planning, the authors suggested an adaptive planning approach. The adaptive approach is less concerned with higher level, predetermined goals and more concerned with subtle incremental change and evolution.

Choe (2003) found that perceived environmental uncertainty had an indirect effect on strategic IT applications. In an uncertain environment, a high level of strategic applications and well-arranged facilitators of alignment could contribute more to the improvement of performance than in a stable environment.

\section{Process models of alignment}

Many studies of alignment have emphasized that alignment is a process rather than an end state (Parker et al., 1988;
MacDonald, 1991; Niederman et al., 1991; Baets, 1992, 1996; Baets and Galliers, 1998; Powell, 1992; Broadbent and Weill, 1993; Henderson and Venkatraman, 1993; Norden, 1993; Papp, 1999; Rondinelli et al., 2001). As Galliers notes (2004), 'an issue that has remained relatively unchallenged and unquestioned is how to align ICT that is relatively fixed, once implemented in an organization, with a business strategy and associated information requirements that are constantly in need of adjustment'.

In this section, we review various process approaches to the study of alignment. We begin with the work that makes the general case that alignment is a process or journey that can never be completely achieved (e.g., ICEX, 2004). We then turn to the research that outlines the factors that must be continually adjusted to keep the organization moving towards alignment. The final section discusses the research, which proposes patterns of alignment that emerge over time in organizations. However, before addressing these three perspectives on the process of alignment, we review two schools of thought about alignment - the classic and the processual (Whittington, 1993).

\section{Classic vs processual schools of thought}

Two perspectives on the relationship between strategy and technology emerge: the classical school and the processual approach (Whittington, 1993). The classical school is based on a model of rational adaptation. The tenets of this approach are that

(i) Organizations are market-driven and constantly adapt to the changes and contingencies of the external environment,

(ii) IT is seen as a resource to be deployed according to the needs and pressures of that environment, and

(iii) The relationship between strategy and IT has to do with recognizing the contingencies of the technology and its potential for application to business objectives (McFarlan, 1984 referenced in Scarbrough, 1998).

The processual school advocates a focus on internal and power issues. Strategy cannot be equated with the business plan and both can become meaningless and ineffective when implemented from the top down. Instead, the processual approach

(i) rejects formal plans and methodologies as simply the tip of the organizational iceberg,

(ii) exposes hidden social values, political interests, and structural inertia, which shape formal instruments of rationality, and

(iii) perceives the role of IT as a resource and an instrument for gaining power - not achieving adaptation.

Drawing on Burt's (1992) work on structural holes, people gain power when they are part of relationships that span the holes in a network. Power is gained since network spanners broker the flow of information between people and control projects that bring people together. To the extent that IT spans holes in the organizational network, it can command power. 
Continuous management of specific organizational components Much of the research on the process view of alignment suggests that certain structures, processes, and relationships need continual calibration.

Baets (1996) concludes that IT strategy alignment is a process, including business strategy, business organization, IT infrastructure, and IT strategy elements. Alignment is a collaborative process between all actors and divisions. Thus, it is not enough to simply understand the factors involved in alignment; one must understand the interrelationships among the factors.

Rondinelli et al. (2001) studied multinational corporations and suggested that they should continuously readjust and realign four sets of strategic components - business strategy, market penetration decisions, management processes, and organizational structures.

ICEX (2004) identifies the CIO as critical in achieving strategic alignment. Four critical responsibilities to be carried out by the CIO are building shared vision, building relationships, enhancing the $\mathrm{CEO}$ relationship, and proactive planning.

Luftman and Brier (1999) conclude that executives should work toward minimizing those activities that inhibit alignment and maximizing those activities that bolster it, such as improving the relationships between the business and IT functional areas, working toward mutual cooperation and participation in strategy development, maintaining executive support, and prioritizing projects more effectively.

Sledgianowski and Luftman (2005) suggest monitoring alignment through the mechanism of service-level agreements. They recommend having periodic formal assessments and reviews of service-level agreements with both IT and business representation, and a formal process in place to make changes based on the results of the assessments.

In a practitioner-based article, Pearlman (2004) gives specific advice for CIOs wishing to achieve alignment. This advice assumes alignment is a process, not an end-state:

(i) Communicate IT performance in business relevant language; shape expectations for an IT-enabled enterprise.

(ii) Demonstrate how IT is contributing to shareholder value; use IT value indicators that are directly linked to business value measures.

(iii) Lead, don't just manage; you must have a vision for achieving your colleagues' business goals using technology.

(iv) Collaborate - work with your colleagues to identify the key business needs, strategies and drivers, then articulate the IT guidelines necessary to address those needs.

(v) Govern - create clear and appropriate IT governance to weave together business and IT strategies and to consistently build credibility and trust.

(vi) Build a high-performing IT organization that is lean and focused.

However, in studying the actions that managers take, Hirschheim and Sabherwal (2001) demonstrates three trajectories that can occur in the process of alignment: paradoxical decisions, excessive transformations, and un- certain turnarounds. This work suggests that understanding the key factors explaining these trajectories is necessary for organizations. Pursuing alignment is complex and frequently chaotic (Rondinelli et al., 2001).

\section{Modeling alignment over time}

There are several models of how alignment changes over time. These include stages of growth, lead-lag, and punctuated equilibrium models.

\section{Stages of growth}

Burn (1993) found that organizations change IT planning styles as they progress through stages of growth in using IT. Further, different approaches to strategy are favored by different organizational configurations. The pattern of strategic alignment reflects the interdependency between organizational configuration and the stage of IT growth. Transitions through this alignment model are characterized by periods of dynamic change, which can be predicted at certain stages of growth. Organizations with strong correlations between IT planning styles and organizational strategies are perceived by the user groups to have the most satisfactory IT support.

Street (2006) provides a preliminary explanation of how the development of IT capabilities are associated with different IT alignment change patterns. In case studies, it was found that organizations go through four phases in alignment: punctuation, change, settling-in, and stability.

\section{The lead-lag model}

Burn suggests that there is an internal (functional) level of alignment, whereby internal processes and strategies are aligned and an external (strategic) level of alignment, in which industry, technology and organizational strategies are aligned. These different levels of alignment suggest the need for a lead-lag model of IT strategy (Burn, 1996, 1997).

This lead-lag model posits that organizations will alternate between IT leading change and IT catching up on change. The model is cyclical, at least for highly competitive industries characterized by rapid technological innovation, and cycles tend to be specific to particular organizational types and particular industries. This research highlights the need for cycles of change within organizations as too long a lead or lag time may be damaging to the firm.

According to Burn, most organizations follow a highly conservative and traditional approach to the alignment process and find difficulty in sustaining alignment. Not all organizations can follow the same path for organizational transformation through IT. As alignment is not a one-time process, knowing the cycles of change and the organizational position in relation to them will facilitate management of the alignment process

\section{Punctuated equilibrium}

Sabherwal et al. (2001) conclude that the punctuated equilibrium model can explain some aspects of IT alignment. According to this model, IT alignment goes through long periods of relative stability, or evolutionary change, interrupted by short periods of quick and extensive, or revolutionary, change. Their research differs from traditional evolutionary perspectives, however, by 
suggesting that during stable times, IT may not be properly aligned. The deep changes brought about by a punctuated equilibrium are beneficial to the firm in the long run, but are sometimes aborted by organizational culture.

Sabherwal et al. (2001) suggest that changes in alignment are, for the most part, small and evolutionary. These changes may prevent catastrophes by controlling misalignments, but they inhibit moving to an altogether different pattern of alignment. Claims about performance effects of alignment should be couched in explicitly longitudinal terms because the same alignment pattern may not be effective over extended periods.

\section{Conclusions}

Future research directions

As the discussion above has demonstrated, we have already learned a great deal about alignment. However, challenges remain. In this section, we suggest opportunities for further research.

It seems clear from the literature that there are at least two distinct conceptualizations of alignment. The first is alignment as an ongoing process, which requires specific IT management capabilities, encompasses specific actions and reactions and has discernable patterns over time. The second is alignment as an end state, which focuses on the antecedents, measures, and outcomes of alignment. The authors see the value of both streams and consider both alignment perspectives to be necessary. Future research that examines alignment should build on the appropriate literature (Kearns and Lederer, 2003). Work that links these two perspectives is likely to be the most difficult but the most beneficial.

\section{Examining the process of alignment}

In general, the process view of alignment has been underrepresented in research to date, given the widespread acknowledgement that alignment is an ongoing activity.

Ciborra (1997) criticizes research in management science because it deploys careful empirical research, claims to identify 'naturally occurring phenomena', but in reality measures theoretical and artificial constructs, so that the messiness of everyday reality is hidden. He concludes that there are many opportunities for a different style of research, a style that questions the core activity of management research and practice. To some extent, the work of Campbell (2005) has begun again 'at the beginning', employing grounded research techniques with the participants in alignment. This work questions the possibility of alignment, and sheds light on the ways that actors struggle with it. More grounded research like this is needed - work that questions the very possibility of alignment and allows the voices of the participants to be heard.

Information systems strategizing has both a location and temporal dimension (Adam, 1990, cited in Galliers, 2004) the latter, in particular, being as yet under-researched. Galliers (2004) reminds us of the essential difficulty in trying to match a relatively fixed set of IT assets to a fastmoving business strategy. Researchers have insufficiently investigated the processes and nuances of alignment.
Longitudinal research is needed to enrich and extend models such as lead-lag and punctuated equilibrium.

\section{Contingency perspectives}

Palmer and Markus (2000) provide evidence to reject a 'one-size fits all' strategic alignment theory. Their research in the retail sector found no relationship between alignment and performance, but did find a relationship between quick response technology and performance. They suggest that alignment may be institutionalized in certain industries, no longer making it a differentiating factor. We agree that alignment research that focuses on specific industries (Farrell, 2003) has the potential to result in better granularity in findings, and a deeper understanding of the way that IT enables value creation.

Shams and Wheeler (2003) ask what are the appropriate alignment states or modes for different strategic organizational contexts and structures? Similarly, Chan et al. (2006) call for future research on different strategic orientations. For example, why does alignment often not lead to increased performance in Defender (Miles and Snow, 1978) firms? Farrell (2003) suggests breaking down alignment factors further to see what differences in importance emerge in terms of strategic orientation, as well as reexamining cases where investment in alignment has had mixed results. More focused ( $v s$ broad brush) investigations of alignment are needed to go beyond 'alignment is good' statements, and to explore subtleties concerning how, when, and where IT alignment really matters.

Alignment processes in entrepreneur-led firms are different from those found in larger bureaucracies (Street, 2006) and small to medium-sized firms (Hale and Cragg, 1996). Researchers are encouraged to focus on specific firm sizes and types to reveal the nature of alignment within each firm type. The ideal firm types found in Mintzberg (1983) might be a useful starting place for this work. Future research that does not assume that alignment is uniform in nature, and that reopens the 'what' of alignment, would be helpful.

\section{Measuring alignment}

Minor and major adjustments to alignment measurement models are needed, as the previous paragraph reveals. A minor adjustment suggested by Croteau and Bergeron (2001) is that future research consider a wider range of approaches to operationalize strategic activities (e.g., Porter, 1980; Wiseman, 1988), and better theoretically justify the specific approaches adopted (Bergeron et al., 2001). Neglecting to specify exact conceptual or mathematical models of fit may lead researchers to obtain inconsistent results.

A more significant measurement change would be involved in going beyond the mathematical models (matching, synergy, and profile deviation) used most frequently in the IS literature. We would like to see the concept of fit explored using theoretical approaches that have not been much in evidence in the IS field (e.g., covariation and gestalt; Bergeron et al., 2001). Oh and Pinsonneault (2005) are currently pushing this frontier, introducing new three-dimensional measures and models of alignment. We argue that it is time to consider models 
that complement, but go beyond, all six fit models proposed by Venkatraman (1989).

Bergeron et al. (2001) suggest that future research should incorporate multiple performance criteria and adopt a dynamic rather than a static perspective, with longitudinal rather than cross-sectional operationalizations of fit.

\section{Examining antecedents}

Rather than merely listing antecedents, we would encourage researchers to explore the inter-relationships among them. Tan (1995) directs the attention of researchers to the interactions between strategy, IT responsiveness, firm size and performance. Farrell (2003) points out that there are several culturally-specific antecedents to alignment. Van Der Zee and De Jong (1999) suggest that a future research challenge is to explicitly understand the prerequisites for integrated IT and management in terms of culture, skills, and responsibilities. Another challenge they highlight is understanding the interface between the business and the IT supply side, or the side of IT focused on technical delivery as requested by the business. They call for the identification of successful integrated management cases, where the results will be examined per industry rather than by using a more traditional, functional IT perspective.

Novel antecedents should be explored. Yetton and Johnston (2001) direct attention of researchers to investigate specific forms of management structures and processes, and IT systems, which are required to drive strategic fit. Kearns and Lederer (2003) suggest that future research address whether the CEO should participate in IT planning, and also increase our understanding of industry effects. They also highlight the importance of knowledge (both tacit and explicit) in the formation and implementation of IT strategy. The relationship between knowledge management and alignment should be investigated further. For instance, Baets (1996) suggests that additional research could be aimed at exploring discrepancies between theoretical knowledge of IT issues and the capacity to translate these into real world action.

\section{New theoretical underpinnings}

It has been argued by many a reviewer that current alignment research is largely atheoretic. Because of its heavy reliance on the strategic management reference discipline and contingency theory (which some do not consider theory), it is not rich in the use of theories such as institutional theory, the resource based view of the firm and stakeholder theory. Greater use of well-established theories in alignment research is needed.

\section{New research approaches}

Chung et al. (2003) recommend that new research examine the recursive relationship between alignment and the extent of applications implementation and IT infrastructure flexibility. Street (2006) has begun this work, examining 'service gaps' as a measure of alignment.

More complex research tools and frameworks can be utilized. Even though there is some agreement that alignment is the congruence of business and IT strategy (and/or plans, understanding, or commitment), there has been little examination of the different loci of alignment. In a complex organization, there is alignment between corporate IT and corporate management, between corporate IT and business units, and within the business unit, between the IT group and the business unit management (Henderson and Venkatraman, 1993; Reich, 1993). Each locus of alignment is likely to have its own unique requirements, depending on alignment at the other loci. To understand alignment in a complex firm is a multi-level task requiring comprehensive analyses.

\section{Implications for Practitioners: Key Takeaways}

What have academics learned that could be useful to business managers and IT practitioners? Below we outline practical suggestions that we have for managers based on our review of the literature.

\section{Share responsibility for alignment}

Alignment should be a joint responsibility between IT and business executives. Lederer and Mendelow (1989) highlight the need for top management to mandate a planning process that ensures business-IT coordination. The actions of IT management alone are not sufficient to achieve this coordination.

Edwards (2000) agrees that the CEO is in the best position to facilitate alignment. The savvy CEO needs to assist the organization in recognizing complex business-IT dependencies and set the larger stage. The ultimate job of the CEO is to make the organization see itself as a broader community that shares core values and has the ability to implement strategy.

Executives and line managers should concentrate on improving the relationships between the business and IT functional areas, working toward mutual cooperation and participation in strategy development, maintaining executive support, and prioritizing projects effectively (Luftman and Brier, 1999).

\section{Share knowledge}

Bassellier and Benbasat (2004) suggest that organizations still need to educate their IT professionals to be more business-oriented. Similarly, Bassellier et al. (2003) argue that since IT knowledge and experience are vital, organizations should put junior business managers on project teams that deal with IT implementations so they get IT experience early in their careers.

Reich and Benbasat (2000) state that IT personnel need to earn the right to play a meaningful role in management forums. Systems analysts must learn about the deep structure of business, perhaps by following their applications into line units when they are implemented. When they can speak the language of business, they will be included in business conversations. The importance of regular communication between IT and business people at all levels cannot be over-emphasized. Gupta et al. (1997) also suggest that the CEO should develop a mentoring program for IT executives to provide them with a broad knowledge of the firm and access to a network of organizational contacts.

\section{Build the right culture and informal structures}

Corporate culture refers to the shared values and norms of behavior that allow the organization's employees, at every 
level, to work together successfully toward a common goal. Baker (2004) cautions that no company can establish and sustain the collaborative culture necessary for enduring IT alignment without everyone involved taking an active leadership role in making that collaborative environment work. Like alignment, leadership is everyone's responsibility.

Kaarst-Brown and Robey (1999) showed that, at a deep level, organizations see themselves as either able to manage and use IT or not. Therefore, creating alignment between business and IT objectives is not just a matter of changing the CIO or implementing an IT steering committee. Over the long term, the culture and stories within the organization must move from those of failure and defeat to those of mastery and success.

Watson et al. (1997) remind us that alignment has a strong cultural and social component, so organizations need to be cautious when disrupting culture, for example, transferring IT personnel from one area or country to another to perform key tasks that influence alignment. However, research by Reich and Kaarst-Brown (2003) shows how transfers of people can affect the culture of IT competence throughout an organization. Their analysis shows an increase in intellectual capital (around IT topics) and resulting competitive advantage within an insurance company in which over 70 IT people moved from IT to non-IT positions. While this is not a 'quick-fix', organizations willing to build a solid foundation of IT excellence should consider cross-functional moves as a part of their organizational development.

\section{Focus on the essentials}

Broadbent and Kitzis (2005) find that the following factors contribute to a well-integrated business and IT strategy: a $\mathrm{CIO}$ who spends productive time with business colleagues; an executive team that develops informed expectations for an IT-enabled enterprise; clear and appropriate IT governance; and taking an IT portfolio management approach to balance risk and return.

Gupta et al. (1997) suggest that managers should limit their concerns to a few key IT management processes. Similarly, Cragg et al. (2002) advise managers of small firms to support their major strategies with IT, rather than attempt to support all strategies. The need for a strategic perspective implies that the owner-manager take an active role in seeking IT alignment.

\section{Educate and equip - provide tools to demonstrate the IT benefits}

Kearns and Lederer (2003) suggest that in order to increase alignment, CIOs should go so far as to educate management about competitors' use of IT. They argue that IT executives should mount educational campaigns to educate senior executives about the benefits of IT alignment (Kearns and Lederer, 2000).

Mirani and Lederer (1998) provide practitioners with a checklist of anticipated benefits of alignment. This can also serve as a measurement tool for evaluation of the IT group. Miller (1993) suggests that business managers and IT personnel need to measure IT effectiveness in order to demonstrate measurable improvements and bring about closer alignment. In the past, the balanced scorecard (Kaplan, 2005) has been used effectively to do so.

\section{Manage the IT budget}

Tallon (2003) suggest that IT executives think about where their business is going and ask whether their current IT spending can get them there without the need for significant retooling.

Tallon et al. (2000) argue that business executives should manage IT investments just like any other investment seek alignment prudently, with an eye on the business case to justify IT spending.

Hirschheim and Sabherwal (2001) state that business and IS executives need to guard against choosing potentially problematic and costly transition paths in managing their organizations' IT resources. Be careful not to radically change aspects of IT strategy, while neglecting others. Strategy components should be adjusted holistically, in consistent ways.

\section{Embrace change}

Bergeron et al. (2004) suggest that when organizations face shifts in the business environment, a new or enhanced business strategy should be simultaneously implemented with a revamped IT strategy and a re-design of IT structure.

Burn (1997) suggests that IT management is similar to walking a tightrope, which balances IT innovation and business transformation simultaneously. Venkatraman et al. (1993) suggest that managers should continuously re-evaluate and re-adjust strategic alignment in response to changes in their environment. Sledgianowski and Luftman (2005) also suggest that IT should adapt and improvise in order to bring value to the firm and meet key strategic objectives.

In closing, we observe that alignment remains an important but elusive goal. Research is moving towards a more nuanced approach to definitions, measures, models, and prescriptions regarding alignment. Much is well understood but there is more to learn. We hope that this summary provides helpful information for future explorers and managers of alignment.

\section{Acknowledgements}

We thank Catherine Shea, Zorana Svedic, and Darius Tadaniewicz for their research assistance and gratefully acknowledge funding provided by the Social Sciences and Humanities Research Council of Canada.

\section{Notes}

1 With the hundreds of articles available today on IT alignment, it was not possible to cite each article. We acknowledge that we have not recognized every study and apologize for any oversights. We also encourage any researcher whose perspective was not presented to bring it to our attention.

2 In this article, we use IT synonymously with IS, and focus on departmental and systems issues. Organizations with no IT departments still have information systems that should meet the needs of the business.

3 We acknowledge with sadness the passing of Dr. Claudio Ciborra in 2005. His contributions to the IT field were significant. 
4 Note that this is one, arguably the dominant, model or measure of alignment. See below for contrasting models such as alignment as moderation or synergy.

5 Also called STROEPIS, the strategic orientation of the enterprise's portfolio of information systems.

6 Profit and loss statement.

7 Researchers who wish to ensure that we are familiar with, and appropriately present, their alignment models are invited to contact the authors.

8 In a January 2007 interview, John Henderson credits the MIT research and colleagues at Harvard (e.g., James Cash, Benn Konsynski, and Warren McFarlan) for discussions that helped to shape the SAM model created with N. Venkatraman. He also acknowledges the influence of other colleagues who contributed at that time to the IS planning literature (e.g., Robert Galliers).

9 Hugh MacDonald was employed by the British firm ICL, one of the corporate sponsors of the MIT project.

10 We use these terms interchangeably.

\section{References}

Abraham, G.A. (2006). Successful Organizational Leadership: Effective execution through strategic management, [Web document] http:// www.refresher.com/Archives/agaaexecution.html (05/15/2007).

Avison, D., Jones, J., Powell, P. and Wilson, D. (2004). Using and Validating the Strategic Alignment Model, Strategic Information Systems 13(3): 223-246.

Baets, W. (1992). Aligning Information Systems with Business Strategy, Journal of Strategic Information Systems 1(4): 205-213.

Baets, W.J. (1996). Some Empirical Evidence on IS Strategy. Alignment in banking, Information \& Management 30(4): 155-177.

Baets, W.R.J. and Galliers, R.D. (eds.) (1998). Information Technology and Organizational Transformation, New York: John Wiley and Sons.

Baker, E.H. (2004). Leading Alignment, CIO Insight 1(45): 19-20.

Bassellier, G. and Benbasat, I. (2004). Business Competence of Information Technology Professionals: Conceptual development and influence on IT-business partnerships, MIS Quarterly 28(4): 673-694.

Bassellier, G., Benbasat, I. and Reich, B.H. (2003). The Influence of Business Managers' IT Competence on Championing IT, Information Systems Research 14(4): 317-336.

Bensaou, M. and Earl, M.J. (1998). The Right Mind-Set for Managing Information Technology (Japanese and American Methods), Harvard Business Review 76(5): 119-129.

Bergeron, F., Raymond, L. and Rivard, S. (2001). Fit in Strategic Information Technology Management Research: An empirical comparison of perspectives, The International Journal of Management Science 29(2): 125-142.

Bergeron, F., Raymond, L. and Rivard, S. (2004). Ideal Patterns of Strategic Alignment and Business Performance, Information \& Management 41(8): 1003-1020.

Bleistein, S.J., Cox, K. and Verner, J. (2006). Validating Strategic Alignment of Organizational IT Requirements Using Goal Modeling and Problem Diagrams, Journal of Systems and Software 79(3): 362-378.

Broadbent, M. and Kitzis, E. (2005). Linking Business and IT Strategies Together: Four factors for success, Ivey Business Journal 69(3): 1-6.

Broadbent, M. and Weill, P. (1993). Improving Business and Information Strategy Alignment: Learning from the banking industry, IBM Systems Journal 32(1): 162-179.

Brown, C.V. and Magill, S.L. (1994). Alignment of the IS Functions with the Enterprise: Toward a model of antecedents, MIS Quarterly 18(4): 371-403.

Burn, J.M. (1993). Information Systems Strategies and the Management of Organizational Change - A strategic alignment model, Journal of Information Technology 8(4): 205-216.

Burn, J.M. (1996). IS Innovation and Organizational Alignment - A professional juggling act, Journal of Information Technology 11(1): 3-12.

Burn, J.M. (1997). A Professional Balancing Act - Walking the tightrope of strategic alignment, in C. Sauer and P.W. Yetton (eds.) Steps to the Future - Fresh thinking on the management of IT-based organizational transformation, 1st edn, San Francisco: Jossey-Bass Publishers, pp. 55-88.
Burn, J.M. and Szeto, C. (2000). A Comparison of the Views of Business and IT Management on Success Factors for Strategic Alignment, Information \& Management 37(4): 197-216.

Burt, R.S. (ed.) (1992). Structural Holes: The social structure of competition, Cambridge, MA: Harvard University Press.

Byrd, A., Lewis, B.R. and Bryan, R.W. (2006). The Leveraging Influence of Strategic Alignment on IT Investment: An empirical examination, Information \& Management 43(3): 308-321.

Campbell, B. (2005). Alignment: Resolving ambiguity within bounded choices, PACIS 2005, Bangkok, Thailand. 1-14.

Campbell, B., Kay, R. and Avison, D. (2005). Strategic Alignment: A practitioner's perspective, Journal of Enterprise Information Management 18(5/6): 653-664.

Chan, Y.E. (1992). Business Strategy, Information Systems Strategy, and Strategic Fit: Measurement and performance impacts, Unpublished Doctor of Philosophy Thesis, University of Western Ontario.

Chan, Y.E. (2001). Information Systems Strategy, Structure and Alignment, in R. Papp (ed.) Strategic Information Technology: Opportunities for competitive advantage, 1st edn, Hershey, PA: Idea Group Publishing, pp. 56-81.

Chan, Y.E. (2002). Why Haven't we Mastered Alignment?: The importance of the informal organization structure, MIS Quarterly Executive 1(2): 97-112.

Chan, Y.E. and Huff, S.L. (1993). Investigating Information Systems Strategic Alignment, Proceedings of the Fourteenth International Conference on Information Systems, Orlando, FL. 345-363.

Chan, Y.E., Huff, S.L., Barclay, D.W. and Copeland, D.G. (1997). Business Strategic Orientation, Information Systems Strategic Orientation, and Strategic Alignment, Information Systems Research 8(2): 125-150.

Chan, Y.E., Sabherwal, R. and Thatcher, J.B. (2006). Antecedents and Outcomes of Strategic IS Alignment: An empirical investigation, IEEE Transactions on Engineering Management 51(3): 27-47.

Choe, J. (2003). The Effect of Environmental Uncertainty and Strategic Applications of IS on a Firm's Performance, Information \& Management 40(4): 257-268

Chung, S.H., Rainer Jr., R.K. and Lewis, B.R. (2003). The Impact of Information Technology Infrastructure Flexibility on Strategic Alignment and Applications Implementations, Communications of the Association for Information Systems 11(article 11): 191-206.

Ciborra, C.U. (1996). Groupware and Teamwork, New York: John Wiley and Sons.

Ciborra, C.U. (1997). De Profundis? Deconstructing the Concept of Strategic Alignment, Scandinavian Journal of Information Systems 9(1): 57-82.

CIO Insight Staff (2004). Is Your Culture Hindering Alignment? CIO Insight 45(1): 65-75.

Cragg, P., King, M. and Hussin, H. (2002). IT Alignment and Firm Performance in Small Manufacturing Firms, Strategic Information Systems 11(2): 109-132.

Croteau, A. and Bergeron, F. (2001). An Information Technology Trilogy: Business strategy, technological deployment and organizational performance, Journal of Strategic Information Systems 10(2): 77-99.

Day, J.G. (1996). An Executive's Guide to Measuring I/S, Strategy \& Leadership 24(5): 39-41.

de Leede, J., Looise, J.C. and Alders, B. (2002). Innovation, Improvement and Operations: An exploration of the management of alignment, International Journal of Technology Management 23(4): 353-368.

Drazin, R. and Van de Ven, A.H. (1985). Alternative Forms of Fit in Contingency Theory, Administrative Science Quarterly 30(4): 514-539.

Earl, M.J. (1989). Management Strategies for Information Technology, London: Prentice-Hall.

Edwards, B.A. (2000). Chief Executive Officer Behaviour: The catalyst for strategic alignment, International Journal of Value-Based Management 13(1): 47-54

Edwards, J.R. (1992). The Study of Congruence in Organizational Behavior Research: Critique and a proposed alternative, Organizational Behavior and Human Decision Processes 58(1): 51-100.

Farrell, I.J. (2003). Aligning IT to Corporate Objectives: Organisational factors in use, Unpublished Doctoral Dissertation, Macquarie University, Sydney.

Feeny, D.F., Edwards, B.R. and Simpson, K.M. (1992). Understanding the CEO/ CIO Relationship, MIS Quarterly 16(4): 435-448.

Floyd, S.W. and Woolridge, B. (1990). Path Analysis of the Relationship between Competitive Strategy, Information Technology, and Financial Performance, Journal of Management Information Systems 7(1): 47-64. 
Luftman, J.N., Lewis, P.R. and Oldach, S.H. (1993). Transforming the Enterprise: The Alignment of Business and Information Technology Strategies, IBM Systems Journal 32(1): 198-221.

Ma, L.C.K. and Burn, J.M. (1998). Managing the Dynamics of Information Systems Strategic Alignment, 1998 IRMA International Conference, Boston, USA. 240-248.

MacDonald, H. (1991). The Strategic Alignment Process, in S. Morton and S. Michael (eds.) The Corporation of the 1990s: Information technology and organizational transformation, 1st edn, London: Oxford Press, pp. 310-322.

Maes, R. (1999). A Generic Framework for Information Management, Prime vera Working Paper, Unpublished manuscript.

Maes, R., Rijsenbrij, D., Truijens, O. and Goedvolk, H. (2000). Redefining Business-IT Alignment through A Unified Framework, Universiteit van Amsterdam/Cap gemini White Paper, Unpublished manuscript.

McFarlan, W.E. (1984). Information Technology Changes the Way You Compete, Harvard Business Review 62(3): 98-103.

McKeen, J.D. and Smith, H. (2003). Making IT Happen: Critical issues in IT management, Chichester, Hoboken, NJ: Wiley.

McKenney, J., Mason, R. and Copeland, D. (1995). Waves of Change: Business evolution through information technology, Cambridge, MA: Harvard Business School Press.

McLean, E.R. and Soden, J.V. (1977). Strategic Planning for MIS, New York: Wiley.

Miles, R.E. and Snow, C.C. (1978). Organizational Strategy, Structure, and Process, New York: McGraw-Hill Book Co.

Miller, J. (1993). Measuring and Aligning Information Systems with the Organization, Information \& Management 25(4): 217-228.

Mintzberg, H. (1973). The Nature of Managerial Work, New York: Harper and Row.

Mintzberg, H. (1983). Structure in Fives: Designing effective organizations, New York: Prentice-Hall.

Mirani, R. and Lederer, A.L. (1998). An Instrument for Assessing the Organizational Benefits of IS Projects, Decision Sciences 29(4): 803-838.

Niederman, F., Brancheau, J.C. and Wetherbe, J.C. (1991). Information Systems Issues for the 1990s, MIS Quarterly 15(4): 475-500.

Norden, P.V. (1993). Qualitative Techniques in Strategic Alignment, IBM Systems Journal 32(1): 180-197.

Oh, W. and Pinsonneault, A. (2007). On the Assessment of the Strategic Value of Information Technologies: Conceptual and Analytical Approaches, MIS Quarterly 31(2): 239-265.

Orlikowski, W. (1996). Improvising Organisational Transformation Over Time: A situated change perspective, Information Systems Research 7(1): 63-92.

Palmer, J.W. and Markus, M.L. (2000). The Performance Impacts of Quick Response and Strategic Alignment in Specialty Retailing, Information Systems Research 11(3): 241-259.

Papp, R. (1999). Business-IT Alignment: Productivity paradox payoff? Industrial Management+Data Systems 99(8): 367-373.

Parker, M.M., Benson, R.J. and Trainor, H.E. (1988). Information Economics: Linking business performance to information technology, Englewood Cliffs, NJ: Prentice-Hall.

Peak, D., Guynes, C.S. and Kroon, V. (2005a). Information Technology Alignment Planning - A case study, Information \& Management 42(4): 619-633.

Peak, D., Guynes, C.S. and Kroon, V. (2005b). Information Technology Alignment Planning - A case study, Information \& Management 42(5): 635-649.

Pearlman, E. (2004). Welcome to the Crossroads, CIO Insight, 1(45): Available Internet: http://www.cioinsight.com/article2/0,1540,1682969,00.asp (05/22/07)

Porter, M.E. (1980). Competitive Strategy, New York: The Free Press.

Powell, T.C. (1992). Organizational Alignment as Competitive Advantage, Strategic Management Journal 13(2): 119-134.

Pyburn, P.J. (1983). Linking the MIS Plan with Corporate Strategy: An exploratory study, MIS Quarterly 7(2): 1-14.

Raymond, L., Pare, G. and Bergeron, F. (1995). Matching Information Technology and Organizational Structure: An empirical study with implications for performance, Eurorpean Journal of Information Systems 4(1): 3-16.

Reich, B.H. (1993). Investigating the Linkage between Business and Information Technology Objectives: A multiple case study in the insurance industry, Unpublished Doctor of Philosophy Thesis, University of British Columbia.

Reich, B.H. and Benbasat, I. (1996). Measuring the Linkage between Business and Information Technology Objectives, MIS Quarterly 20(1): 55-81. 
Reich, B.H. and Benbasat, I. (2000). Factors that Influence the Social Dimension of Alignment between Business and Information Technology Objectives, MIS Quarterly 24(1): 81-113.

Reich, B.H. and Kaarst-Brown, M.L. (2003). Creating Social and Intellectual Capital through IT Career Transitions, Journal of Strategic Information Systems 12(2): 91-109.

Rondinelli, D., Rosen, B. and Drori, I. (2001). The Struggle for Strategic Alignment in Multinational Corporations: Managing readjustment during global expansion, European Management Journal 19(4): 404-416.

Sabherwal, R. and Chan, Y.E. (2001). Alignment between Business and IS Strategies: A study of prospectors, analyzers, and defenders, Information Systems Research 12(1): 11-33.

Sabherwal, R., Hirschheim, R. and Goles, T. (2001). The Dynamics of Alignment: Insights from a punctuated equilibrium model, Organization Science 12(2): 179-197.

Sabherwal, R. and Kirs, P. (1994). The Alignment between Organizational Critical Success Factors and Information Technology Capability in Academic Institutions, Decision Sciences 25(2): 301-330.

Sauer, C. and Burn, J.M. (1997). The Pathology of Strategic Management, in C. Sauer and P.W. Yetton (eds.) Steps to the Future, 1st edn, San Francisco: Jossey-Bass, pp. 89-112.

Sauer, C. and Yetton, P.W. (1997). The Right Stuff - An introduction to new thinking about management, in C. Sauer and P.W. Yetton (eds.) Steps to the Future: Fresh thinking on the management of IT-based organizational transformation, 1st edn, San Francisco: Jossey-Bass, pp. 1-21.

Scarbrough, H. (1998). Linking Strategy and IT-Based Innovation: The importance of the "management of expertise", in R.D. Galliers and W.R.J. Baets (eds.) Information Technology and Organizational Transformation: Innovation for the 21st century organization, 2nd edn, Toronto: John Wiley \& Sons, pp. 19-36.

Scott Morton, M.S. (1991). The Corporation of the 1990s: Information technology and organizational transformation, London: Oxford Press.

Shams, R.M. and Wheeler, F.P. (2003). Information-Induced Strategic Alignment: Towards a semiological analysis, in N. Shin (ed.) Creating Business Value with Information Technology: Challenges and solutions, 1st edn, Hershey, PA: Idea Group Publishing, pp. 23-49.

Shank, J.K., Niblock, E.G. and Sandalls Jr., W.T. (1973). Balance Creativity and Practicality in Formal Planning, Harvard Business Review 51(1): 87-95.

Sledgianowski, D. and Luftman, J. (2005). IT-Business Strategic Alignment Maturity: A case study, Journal of Cases on Information Technology 7(2): 102-120.

Smaczny, T. (2001). Is an Alignment between Business and Information Technology the Appropriate Paradigm to Manage IT in Today's Organisations? Management Decision 39(10): 797-802.

Street, C.T. (2006). Evolution in IS Alignment and IS Alignment Capabilities Over Time: A test of punctuated equilibrium theory, Unpublished Doctor of Philosophy Thesis, Queen's University.

Tallon, P.P. (2003). The Alignment Paradox, CIO Insight 1(47): November 15, 2003, www.cioinsight.com/article2/0,1397,137546,00.asp.

Tallon, P.P., Kraemer, K.L. and Gurbaxani, V. (2000). Executives' Perceptions of the Business Value of Information Technology: A process-oriented approach, Journal of Management Information Systems 16(4): 145-173.

Tallon, P.P. and Pinsonneault, A. (2005). In Pursuit of Value: Reconceptualizing the Form and Function of Strategic IT Alignment Under Environmental Dynamism, Article under review at Organization Science.

Tan, F.B. (1995). The Responsiveness of Information Technology to Business Strategy Formulation: An empirical study, Journal of Information Technology 10(3): 171-178.

Tan, F.B. and Gallupe, B. (2006). Aligning Business and Information Systems Thinking: A cognitive approach, Engineering Management, IEEE Transactions 53(2): 223-237.

Tan, F. and Hunter, M.G. (2002). The Repertory Grid Technique: A method for the study of cognition in information systems, MIS Quarterly 26(1): 39-57.

Tavakolian, H. (1989). Linking the Information Technology Structure with Organizational Competitive Strategy: A survey, MIS Quarterly 13(3): 309-317.

Teo, T.S.H. and Ang, J.S.K. (1999). Critical Success Factors in the Alignment of IS Plans with Business Plans, International Journal of Information Management 19(1): 173-185.

Van Der Zee, J.T.M. and De Jong, B. (1999). Alignment is Not Enough: Integrating business and information technology management with the balanced business scoreboard, Journal of Management Information Systems 16(2): 137-156.
Venkatraman, N. (1989). The Concept of Fit in Strategy Research: Toward verbal and statistical correspondence, Academy of Management Review 14(3): 423-444.

Venkatraman, N., Henderson, J.C. and Oldach, S. (1993). Continuous Strategic Alignment: Exploiting information technology capabilities for competitive success, European Management Journal 11(2): 139-149.

Vitale, M.R., Ives, B. and Beath, C.M. (1986). Linking information technology and corporate strategy: An organizational view, Proceedings of the Seventh International Conference on Information Systems, San Diego, USA. 265-276.

Wang, E.T.G. and Tai, J.C.F. (2003). Factors Affecting Information Systems Planning Effectiveness: Organizational contexts and planning systems dimensions, Information Management 40(4): 287-303.

Watson, R.T., Kelly, G.G., Galliers, R.D. and Brancheau, J.C. (1997). Key Issues in Information Systems Management: An international perspective, Journal of Management Information Systems 13(4): 91-115.

Whittington, R. (ed.) (1993). What is Strategy - And does it matter, Routledge Series in Analytical Management, London: Routledge.

Wiseman, C. (1988). Strategic Information Systems, Homewood, IL: Dow JonesIrwin.

Yetton, P.W. (1994). False Prophecies, Successful Practice and Future Directions in IT Management, Proceedings of the IFIP TC8 Open Conference: Business Process Re-Engineering: Information systems opportunities and challenges, Queensland Gold Coast, Australia. 103-112.

Yetton, P.W. and Johnston, K.D. (2001). Competing Forms of Fit in a Professional Bureaucracy: IT management dilemmas, International Journal of Healthcare Management and Technology 3(2/3/4): 142-159.

\section{About the authors}

Yolande E. Chan is a professor and E. Marie Shantz is a research fellow in MIS at Queen's University in Canada. She holds a Ph.D. from the University of Western Ontario, an M.Phil. in Management Studies from the Oxford University, and S.M. and S.B. degrees in Electrical Engineering and Computer Science from MIT. Prior to joining Queen's, she worked with Andersen Consulting (now Accenture). Currently she serves as Director, The Monieson Centre. Dr. Chan conducts research on information systems alignment, knowledge management, information privacy, and information systems performance. She has published her findings in journals such as Information Systems Research, MIS Quarterly Executive, Journal of Management Information Systems, Journal of the Association for Information Systems, Journal of Strategic Information Systems, Information \& Management, IEEE Transactions on Engineering Management and The Academy of Management Executive. Dr. Chan is a member of several journal editorial boards and is an officer of the Association for Information Systems.

Blaize Horner Reich Professor, Segal Graduate School of Business, Simon Fraser University, Vancouver, Canada. Visiting Associate, Templeton College, Oxford University. Before pursuing her Ph.D., Dr. Reich worked for 15 years in the IT industry as a practitioner and consultant, focusing on the financial services and utilities sectors. She is currently an editorial board member for several academic journals and a corporate director of two companies. Dr. Reich's research has been published in a wide range of journals, including MIS Quarterly, Information Systems Research, Journal for Management Information Systems and The Project Management Journal. Dr. Reich has two current research programs: (1) IT Project Performance and (2) IT Governance and Risk management. She and colleagues at Oxford and SFU recently received two national grants to extend their IT Project Performance research. 